\title{
Pemanfaatan Bagian-Bagian Jalan Nasional, Studi Kasus di Ruas Jalan MERR Surabaya
}

\author{
Utilization of National Road Segment, Case Study in MERR Street \\ Section Surabaya
}

\author{
Dyah Kusuma Dewi $^{1, \mathrm{a})}$, Ria Asih Aryani Soemitro ${ }^{2, \mathrm{c})}$, Hitapriya Suprayitno ${ }^{2, \mathrm{~b})}$, \& Herry \\ Budianto $^{3, \mathrm{~d})}$ \\ ${ }^{1)}$ Karyasiswa MMAI, Dept. Teknik Sipil, Institut Teknologi Sepuluh Nopember (ITS), \\ Surabaya \\ ${ }^{2)}$ Departemen Teknik Sipil, Institut Teknologi Sepuluh Nopember (ITS), Surabaya \\ ${ }^{3)}$ Mantan Pejabat, Dinas PU Bina Marga, Pemerintah Provinsi Jawa Timur, Surabaya.
}

Koresponden : ${ }^{a}$ dyah.ku87@gmail.com, ${ }^{\mathrm{c})}$ ria@ce.its.ac.id, ${ }^{\text {b) }}$ suprayitno.hita@gmail.com,

d)budiantoherry@yahoo.com

\begin{abstract}
ABSTRAK
Jalan nasional merupakan salah satu infrastruktur trasportasi darat yang kewenangan pengelolaannya adalah pemerintah. Jalan mempunyai bagian-bagian jalan yang pemanfaatannya tidak hanya untuk menghubungkan daerah satu dengan daerah lain, namun juga dapat dimanfaatakan untuk keperluan pihak-pihak lain. Pemanfaatan bagianbagian jalan dapat dilakukan oleh pihak perorangan, perusahaan maupun pemerintah dengan mendapat izin dari pengelola jalan nasional yaitu Balai Besar Pelaksanaan Jalan Nasional/Balai Pelaksanaan Jalan Nasional. Metode penelitian yang digunakan adalah kualitatif. Hasil observasi menunjukkan di Jln. Ir Soekarno (MERR Surabaya) ada pemanfaatan bagian-bagian jalan berupa utilitas, iklan dan media informasi serta bangunan-bangunan yang berupa jalan keluar masuk. Pemanfaatan jalan ada yang belum berizin ke penyelenggara jalan nasional yaitu Balai Besar Pelaksanaan Jalan Nasional.
\end{abstract}

Kata Kunci : manajemen asset infrastruktur, infrastruktur, jalan nasional, ruang milik jalan, pemanfaatan bagian-bagian jalan.

\section{PENDAHULUAN}

Infrastruktur sangat penting untuk kehidupan daerah: kehidupan ekonomi, sosial dan administrasi. Pengadaan infrastruktur membutuhkan banyak dana dan secara teknis, infrastruktur bukanlah objek yang sederhana. Namun, pendanaan selalu terbatas. Infrastruktur sengaja dibangun untuk memenuhi fungsi tertentu yang sangat dibutuhkan. Oleh karena itu, infrastruktur harus dikelola dengan baik agar infrastruktur dapat selalu berfungsi, ekonomis, efektif, efisien dan berkelanjutan (Suprayitno \& Soemitro 2018). Jalan merupakan salah satu asset infrastruktur transportasi yang amat penting untuk mengalirkan orang dan barang serta untuk menghubungkan antara daerah satu dengan daerah lainnya.

Undang-Undang Nomor 38 Tahun 2004 tentang Jalan mendefinisikan jalan adalah prasarana transportasi darat yang meliputi segala bagian jalan, termasuk bangunan pelengkap dan perlengkapannya yang diperuntukkan bagi lalu lintas, yang berada pada permukaan tanah, di atas permukaan tanah, di bawah permukaan tanah dan/atau air, serta di atas permukaan air, kecuali jalan kereta api, jalan lori, dan jalan kabel. Jalan juga mempunyai bagian-bagian jalan, yang terdiri atas ruang manfaat jalan, ruang milik jalan, dan ruang pengawasan jalan. Ruang manfaat jalan meliputi badan jalan, saluran tepi jalan, dan ambang pengamannya. Ruang milik 
jalan meliputi ruang manfaat jalan dan sejalur tanah tertentu di luar ruang manfaat jalan. Ruang pengawasan jalan merupakan ruang tertentu di luar ruang milik jalan yang ada di bawah pengawasan penyelenggara jalan. Pada Gambar 1 ditunjukkan batas bagian-bagian jalan.

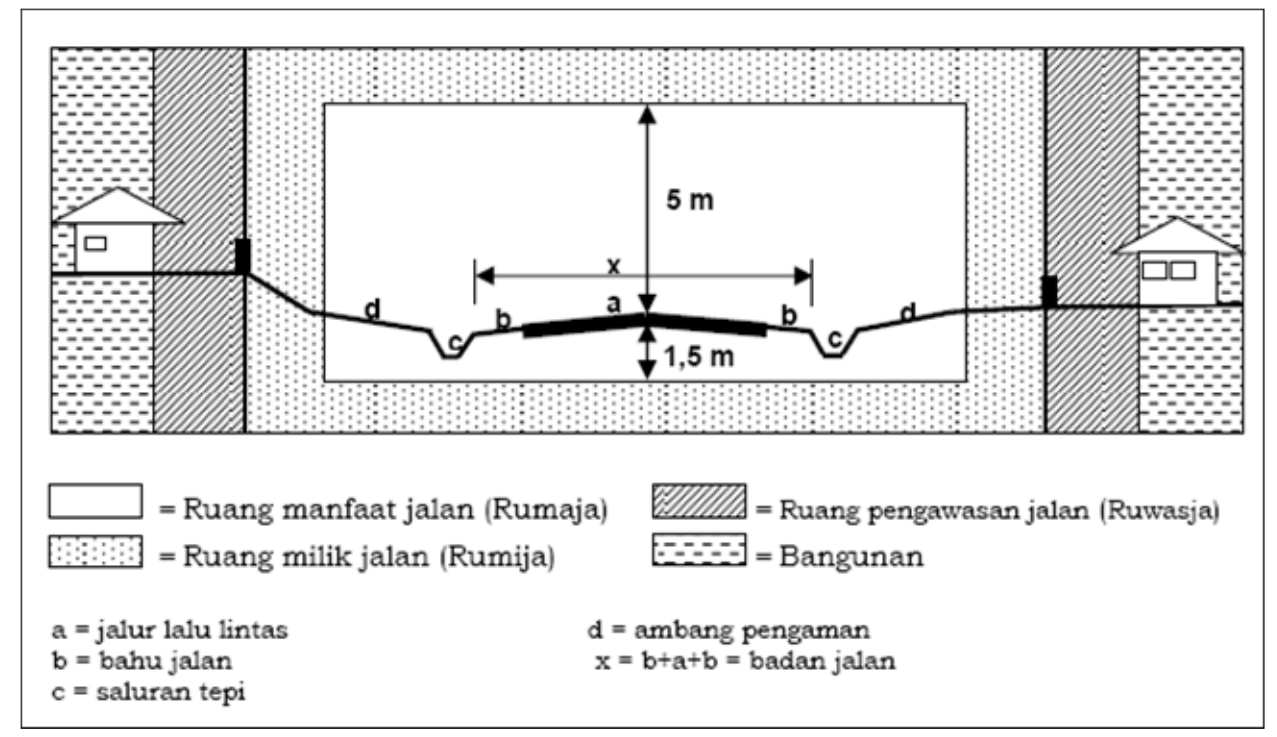

Gambar 1. Bagian-Bagian Jalan Menurut PP 34/06

Sumber : simantu.go.id

Ruang manfaat jalan hanya diperuntukkan bagi median, perkerasan jalan, jalur pemisah, bahu jalan, saluran tepi jalan, trotoar, lereng, ambang pengaman, timbunan dan galian, goronggorong, perlengkapan jalan, serta bangunan pelengkap lainnya (PP 34/06, Pasal 34). Sedangkan ruang milik jalan diperuntukkan bagi ruang manfaat jalan, pelebaran jalan, dan penambahan jalur lalu lintas di masa akan datang serta kebutuhan ruangan untuk pengamanan jalan (PP 34/06, Pasal 39). Ruang pengawasan jalan diperuntukkan bagi pandangan bebas pengemudi, pengamanan konstruksi jalan, serta pengamanan fungsi jalan (PP 34/06, 44).

Pengaturan pemanfaatan bagian-bagian jalan dimaksudkan untuk menjamin bahwa pemanfaatan ruang manfaat jalan dan ruang milik jalan selain untuk peruntukannya, penggunaan ruang manfaat jalan yang memerlukan perlakuan khusus terhadap konstruksi jalan dan jembatan, serta penggunaan ruang pengawasan jalan dilaksanakan dengan tertib (PerMenPU 20/10, Pasal 2). Untuk menjamin agar tidak terjadi pelanggaran, diperlukan sebuah pengawasan (Hardi \& Ernawati, 2016).

Pemanfaatan ruang manfaat jalan dan ruang milik jalan selain peruntukannya meliputi bangunan dan jaringan utilitas, iklan, media informasi, bangunan-bangunan dan bangunan gedung didalam ruang milik jalan (PerMenPU 20/10, Pasal 3).

Pengelolaan Bagian-bagian jalan, Balai Besar Pelaksanaan Jalan Nasional VIII sebagai perangkat pemerintah berdasarkan Peraturan Menteri Pekerjaan Umum Nomor: 20/PRT/M/2010 tentang Pedoman Pemanfaatan Bagian-Bagian Jalan, mempunyai kewenangan sebagai pengelola jalan dan pengelola izin pemanfaatan bagian-bagian jalan Nasional di wilayah kerjanya yaitu Jawa Timur dan Bali. Pemanfaatan bagian-bagian jalan nasional di Balai Besar Pelaksanaan Jalan Nasional VIII masih kurang mendapat perhatian yang khusus, sehingga meskipun sudah mempunyai pelayanan perizinan masih banyak terdapat obyek perizinan yang berdiri tanpa memiliki izin. Proses perizinan Seringkali terdapat permasalahan dalam implementasi proses perizinan di lapangan (Hadi et al., 2018).

Oleh karena itu penelitian ini perlu dilakukan untuk melihat permasalahan perizinan ruang milik jalan yang dilakukan oleh BBPJN VIII. 


\section{KAJIAN TEORI}

\section{Manajemen Aset infrastruktur Jalan}

Manajemen Aset Infrastruktur (MAI) adalah suatu program atau pengetahuan untuk mengelola suatu infrastruktur agar tetap bias menjalankan fungsinya dengan baik secara terus menerus sepanjang masih dibutuhkan, secara ekonomis, efisien dan efektif dan memenuhi prinsip green atau sustainability. MAI harus didasarkan pada pengetahuan yang baik atas karakteristik infrastruktur yang sedang dikelola atau dibahas. Karakteristik infrastruktur bisa sangat berbeda antara yang satu dengan yang lain. Karakteristik penting infrastruktur yang harus dikenali dengan baik antara lain adalah: tipe, klas, fungsi, struktur, ekonomi, siklus hidup, operasi, pemeliharaan, penghapusan (Suprayitno \& Soemitro, 2018). Tujuan manajemen aset secara umum yakni untuk pengambilan keputusan yang tepat agar asset yang dikelola berfungsi secara efektif dan efisien (Sugiama, 2013).

\section{Aturan Pemanfaatan Bagian-Bagian Jalan Di BBPJN VIII}

Menurut PP No. 34 Tahun 2006 tentang Jalan, pemanfaatan ruang manfaat jalan dan ruang milik jalan, yang meliputi bangunan yang ditempatkan di atas, pada, dan di bawah permukaan tanah di ruang manfaat jalan dan di ruang milik jalan, harus memenuhi persyaratan sebagai berikut :

1. Tidak mengganggu kelancaran dan keselamatan pengguna jalan serta tidak membahayakan kontruksi jalan;

2. Sesuai dengan peraturan perundang-undangan; dan

3. Sesuai dengan pedoman yang ditetapkan oleh menteri dan pedoman yang ditetapkan oleh menteri yang menyelenggarakan urusan di bidang lalu lintas dan angkutan jalan.

Berdasarkan objek penggunanya, terdapat empat klasifikasi objek pengguna ruang milik dan ruang manfaat jalan. Objek-objek pengguna ruang milik jalan dan ruang manfaat jalan ini diatur dalam PP No. 34 Tahun 2006 tentang Jalan, yaitu :

1. Utilitas adalah fasilitas yang menyangkut kepentingan umum meliputi listrik, telekomunikasi, informasi, air, minyak, gas, dan bahan bakar lainnya, sanitasi dan sejenisnya.

2. Bangunan dan jaringan adalah bangunan dan jaringan pendukung utilitas yang terletak di atas dan/atau di bawah permukaan tanah.

3. Iklan adalah media dalam bentuk apapun yang digunakan produsen untuk memperkenalkan suatu produk kepada khalayak umum.

4. Media informasi adalah media dalam bentuk apapun yang tidak bersifat komersial.

Maksud dan tujuan dalam pemanfaatan bagian-bagian jalan berdasarkan Peraturan Menteri Pekerjaan Umum Nomor 20 Tahun 2010 adalah untuk menjamin bahwa pemanfaatan ruang manfaat jalan dan ruang milik jalan selain peruntukannya, penggunaan ruang manfaat jalan yang memerlukan perlakuan khusus terhadap konstruksi jalan dan jembatan, serta penggunaan ruang pengawasan jalan dapat dilaksanakan secara tertib, dan tujuan pengamanan fungsi jalan adalah untuk menjamin kelancaran, keselamatan dan keamanan konstruksi jalan. 


\section{Tata Cara Pemanfaatan Bagian-Bagian Jalan Nasional (Non Tol)}

Menurut SE Direktur Jenderal Bina Marga Nomor 01/SE/Db/2017 tentang prosedur perizinan pemanfaatan bagian-bagian jalan Nasional waktu yang ditetapkan untuk penyelesaian pemanfaatan bagian-bagian jalan nasional (non tol) ditetapkan selama 17 (tujuh belas) hari kerja. Dimana terdapat beberapa ketentuan yang harus dipenuhi yaitu meliputi:

1. Mengajukan Izin Pemanfaatan (Pemohon)

Pengajuan izin disampaikan oleh Pemohon kepada Kepala Balai Besar/Balai Pelaksanaan Jalan Nasional bagi kepentingan pemasangan bangunan utilitas dan/atau utilitas dengan melampirkan persyaratan administrasi dan persyaratan teknis.

2. Memeriksa Kelengkapan Persyaratan Administrasi dan Teknis

Balai Besar/Balai Pelaksanaan Jalan Nasional melakukan pemeriksaan kelengkapan usulan (persyaratan administrasi dan teknis) dalam waktu selambat-lambatnya 3 (tiga) hari kerja. Apabila terdapat kekurangan pada dokumen adminstrasi dan teknis yang tidak memenuhi syarat makan akan diterbitkan surat pengembalian dokumen pada pemohon yang selanjutnya pemohon dapat melengkapi kelengkapan data yang diperlukan. Proses evaluasi dan peninjauan lapangan dapat dilakukan apabila seluruh persyaratan telah dipenuhi.

3. Mengevaluasi Teknis dan Melakukan Peninjauan Lapangan

Balai Besar/Balai Pelaksanaan Jalan Nasional melaksanakan evaluasi dan peninjauan lapangan yang melibatkan para stakeholder yaitu PPK, TU/BMN, P2JN dan Pemohon serta pihak yang terkait lainnya jika diperlukan. Hal-hal yang perlu diperhatikan untuk mengevaluasi dan melakukan peninjauan lapangan yaitu :

4. Membuat Berita Acara Peninjauan Lapangan

Membuat berita acara peninjauan lapangan yang berisi kesesuaian persyaratan teknis terhadap kondisi eksisting lapangan dan ditandatangani oleh semua pihak yang terlibat.

5. Membuat berita acara hasil evaluasi

Membuat berita acara hasil evaluasi yang berisi antara lain rekomendasi memenuhi persyaratan atau tidak memenuhi persyaratan teknis dan ditandatangani oleh Kepala Balai Besar/Balai Pelaksanaan Jalan Nasional.

6. Menerbitkan Surat Penolakan Permohonan

Menerbitkan surat penolakan permohonan dari Kepala Balai Besar/Balai Pelaksanaan Jalan Nasional apabila hasil evaluasi menyatakan tidak memenuhi persyaratan teknis.

7. Melanjutkan proses selanjutnya apabila hasil evaluasi menyatakan memenuhi persyaratan teknis.

\section{METODE PENELITIAN}

Adapun metode yang digunakan dalam penelitian ini adalah metode kualitatif. Lokasi yang menjadi obyek penelitian adalah Jalan Nasional Ir. Soekarno atau dikenal dengan Jalan MERR Surabaya. Jalan ini mepunyai panjang 9,209 Km dan merupakan lingkup Satuan Kerja Balai Besar Pelaksanaan Jalan Nasional VIII selaku penyelenggara jalan sekaligus pengelola Izin Pemanfaatan Bagian-Bagian Jalan Nasional di Provinsi Jawa Timur dan Bali. Data penelitian ini merupakan data primer diperoleh dari observasi langsung peneliti di sepanjang jalan Ir. Soekarno yang dilakukan pada April 2020.

Setelah mendapatkan data dari hasil observasi, kemudia dilakukan konfirmasi terhadap seluruh pemanfaatan di sepanjang jalan Ir. Soekarno kepada BBPJN VIII dan dilakukan penyajian data kemudian dilakukan analisis sehingga memungkinkan untuk ditarik kesimpulan. 


\section{HASIL PENELITIAN}

Pemanfaatan bagian-bagian jalan yang berada di ruas jalan Ir. Soekarno antara lain adalah Iklan dan Media Informasi, Akses Jalan Keluar Masuk dan Jaringan Utilitas. Data dikumpulkan dengan cara observasi melalui dokumentasi foto dan disajikan dalam bentuk tabel. Observasi dilakukan di sepanjang jalan MERR sisi Kiri dan Kanan mulai dari KM 7+616 sampai dengan KM $16+820$.

\section{Utilitas}

Utilitas adalah fasilitas yang menyangkut kepentingan umum masyarakat banyak yang mempunyai sifat pelayanan local maupun wilayah di luar bangunan pelengkapan dan perlengkapan jalan meliputi listrik, telekomunikasi, informasi, air, minyak, gas, dan bahan bakar lainnya, sanitasi dan sejenisnya. Dari hasil observasi mengenai pemasangan jarigan utilitas dapat dilihat pada Gambar 2 di bawah ini :

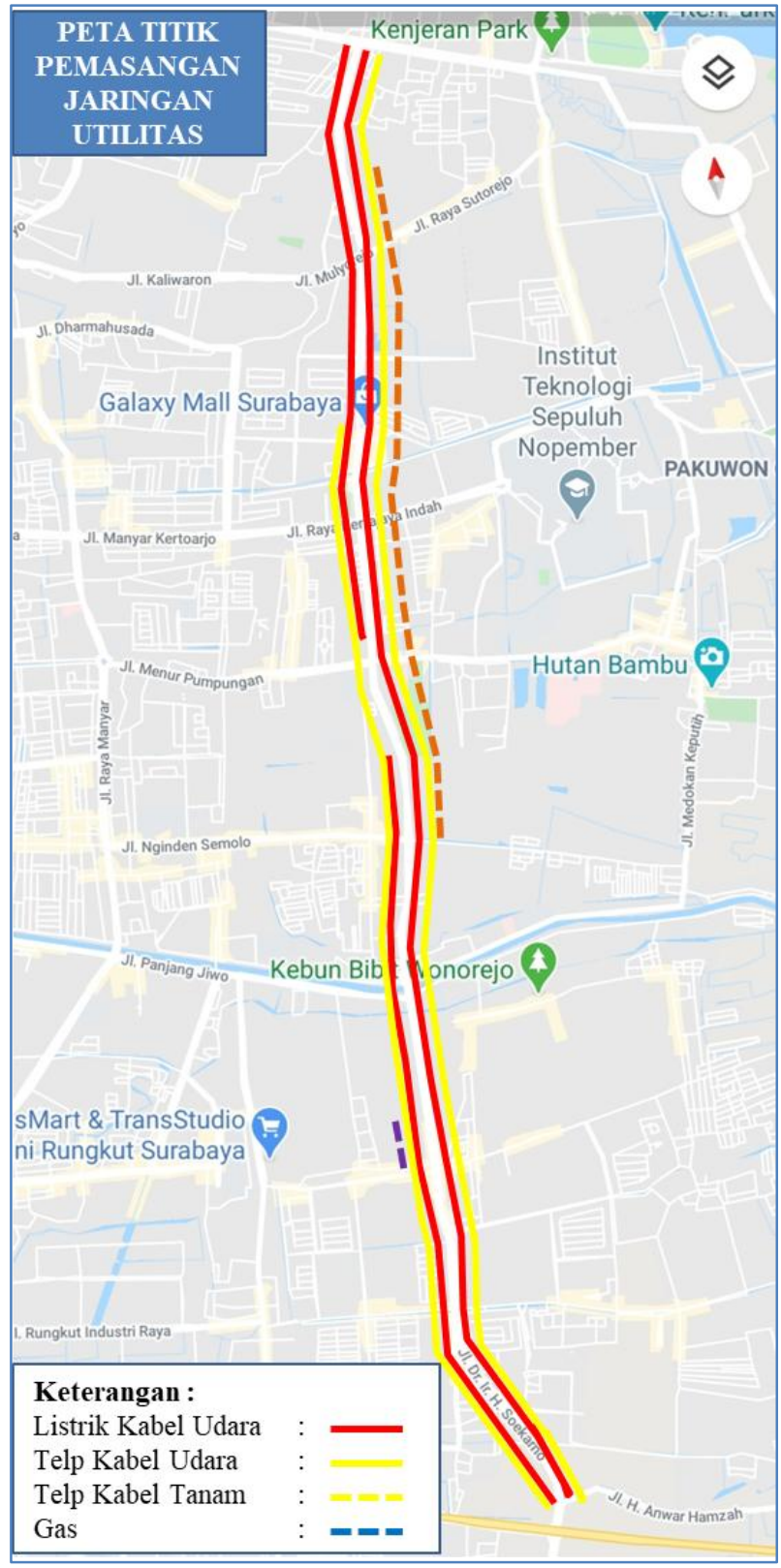

Gambar 2. Titik Lokasi Pemasangan Jaringan Utilitas di Ruas Jalan Ir. Soekarno 
Gambar 2 menunjukkan adanya 4 pemasangan jaringan utilitas baik di atas tanah maupun di dalam tanah yang berada di sepanjang Jl. Ir. Soekarno. Terhadap data tersebut kemudian dilakukan konfirmasi atas pemanfaatan jaringan utilitas kepada penyelenggara jalan nasional yaitu BBPJN VIII, hasil konfirmasi tersebut dapat dilihat pada Tabel 1 berikut ini

Table 1. Pemanfaatan Rumija oleh Utilitas di Ruas Jl. Ir. Soekarno

\begin{tabular}{rllc}
\hline No & \multicolumn{1}{c}{ Nama Jenis Utilitas } & \multicolumn{1}{c}{ Lokasi } & Keterangan \\
\hline 1 & Jaringan Listrik Kabel Udara & Sisi Kanan dan Kiri sepanjang Jl. MERR & Berizin \\
2 & Jaringan Telkom Kabel Udara & Sisi Kanan dan Kiri sepanjang Jl. MERR & Berizin \\
3 & Jaringan Telkom Kabel Tanam & Sisi Kiri Jl. MERR & Berizin \\
4 & Jaringan Distribusi Gas & Sisi Kanan Jl. MERR & Tidak Berizin \\
\hline
\end{tabular}

Table 1 menunjukkan di sepanjang jalan MERR atau Ir. Soekarno terdapat pemanfaatan jalan untuk utilitas yang berupa jaringan listrik kabel udara, jaringan Telkom kabel udara dan kabel tanam serta distribusi Gas oleh PGN (Perusahaan Gas Negara), kesemua pemasangan utilitas sudah berizin kepada BBPJN VIII kecuali PGN. PGN terpasang dengan status perizinan kepada Pemkot Kota Surabaya hal tersebut terjadi karena pemasangan PGN sudah dilakukan sejak tahun 2012, yang pada saat itu status jalan masih merupakan jalan kota.

COntoh pemasangan jaringan utilitas dilihat dengan adanya tanda patok yang terdapat identitas PGN yakti Perusahaan Gas Negara. Identitas patok tersebut dapat dilihat dalam Gambar 3 berikut ini :

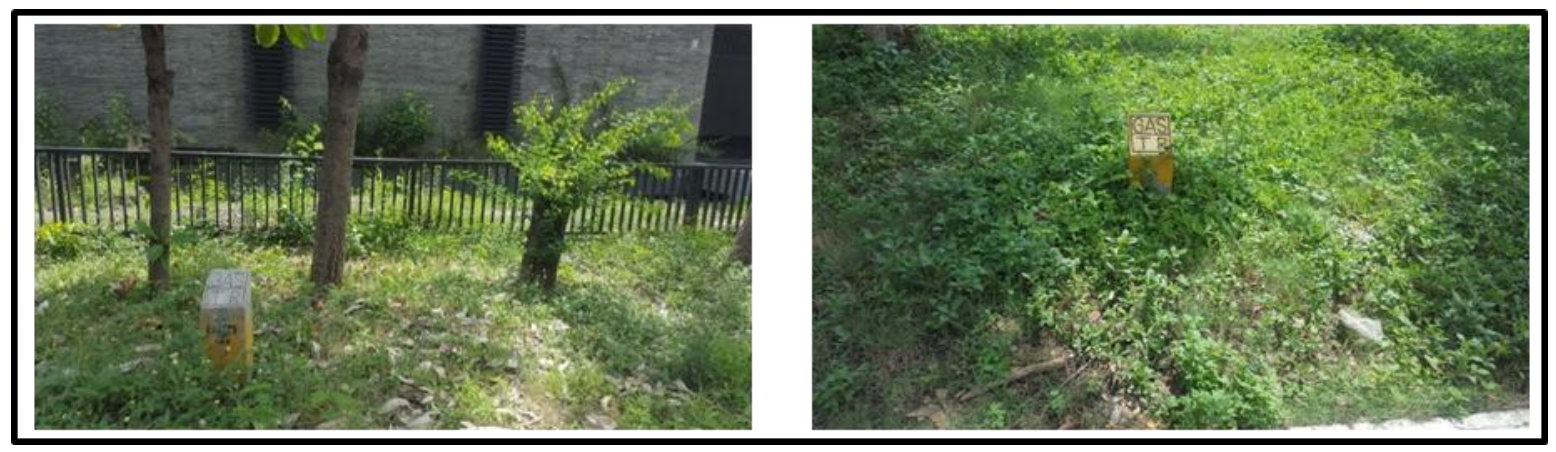

Gambar 3. Tanda Pemasangan Utilitas di Ruas Jl. Ir. Soekarno

Pemanfaatan bagian jalan berupa utilitas jarang yang tidak berizin, namun sering kali pemasangan dilakukan terlebih dahulu sebelum izin jadi, dalam kata lain saat izin masih dalam proses pesamasangan jaringan utilitas telah dilaksanakan. Dan permasalahan lain dalam izin utilitas adalah pengembalian kondisi galian pasca pemasangan yang tidak sesuai dengan spesifikasi dan bahan bahu jalan, sehingga sering kali menjadi penyebab kerusakan jalan. Hal tersebut dapat diminimalisir dengan adanya pengawasan yang dilakukan oleh pihak BBPJN VIII selama masa pekerjaan. 


\section{Iklan dan Media Informasi}

Iklan adalah media dalam bentuk apapun yang digunakan produsen untuk memperkenalkan suatu produk kepada khalayak umum. Pemanfaatan bagian-bagian jalan berupa iklan dan media informasi di sepanjang jalan Ir. Soekarno dapat dilihat pada Gambar 4 di bawah ini :

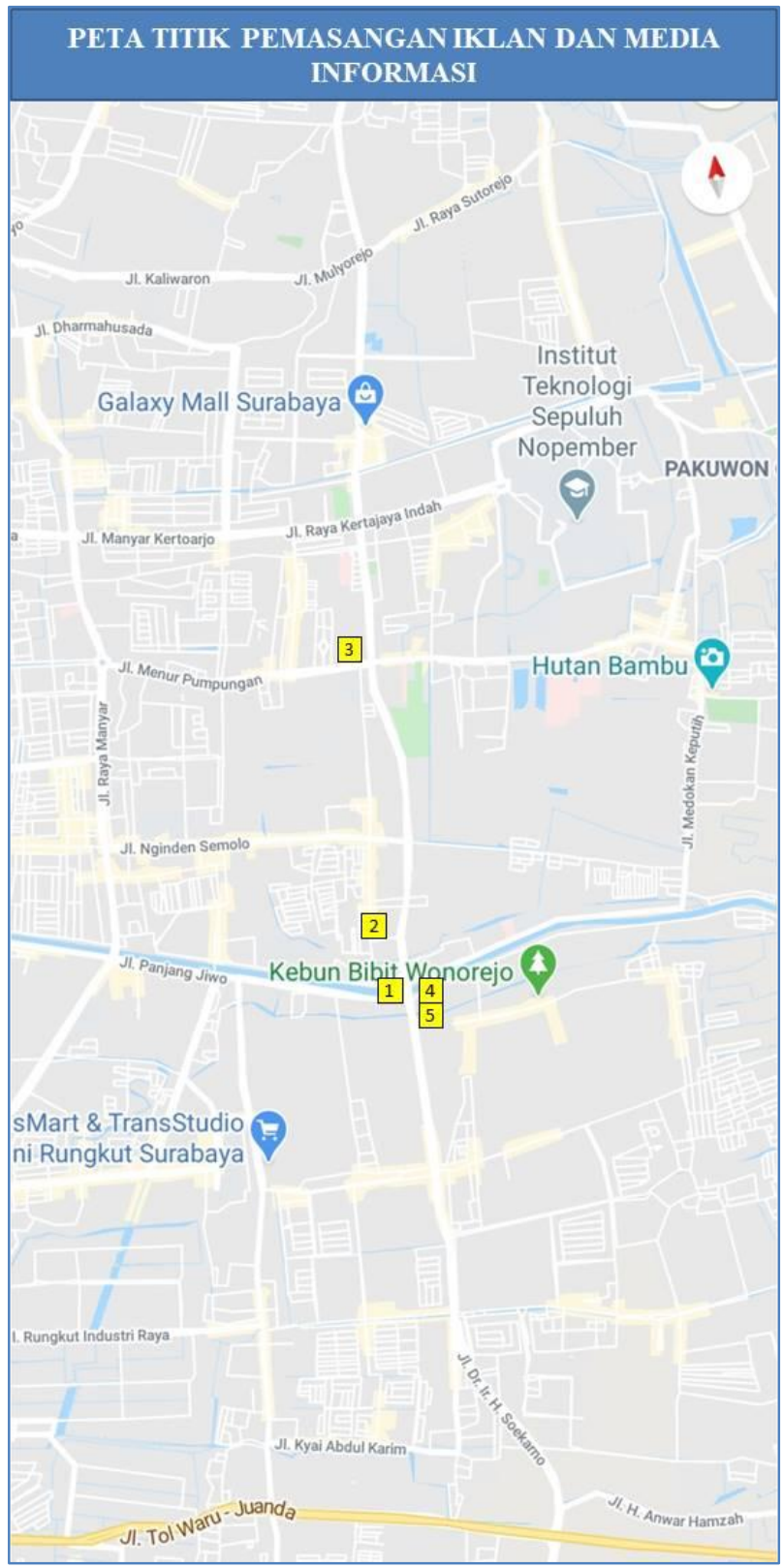

Gambar 4. Titik Lokasi Pemasangan Iklan dan Media Informasi di Ruas Jalan Ir. Soekarno

Gambar 4 menunjukkan 5 titik lokasi bangunan iklan yang ada di Jalan MERR. Kepada 5 banguan tersebut kemudian dilakukan konfirmasi status perizinan terhadap BBPJN VIII hasil konfirmasi disajikan pada Tabel 2 berikut ini : 
Table 2. Iklan dan Media Informasi di Ruas Jl. Ir. Soekarno

\begin{tabular}{lllc}
\hline No & \multicolumn{1}{c}{ Nama Perusahaan } & \multicolumn{1}{c}{ Lokasi } & Keterangan \\
\hline 1 & Baliho Rokok & Tambak Sumur - Kenjeran & Tidak Berizin \\
2 & Papan Pengenal Perusahaan Surabaya & Tambak Sumur - Kenjeran & Tidak Berizin \\
& Square & & \\
3 & Papan Pengenal Tempat Parkir A.R. Hakim & Tambak Sumur - Kenjeran & Tidak Berizin \\
4 & Baliho Perumahan Wisata Semanggi & Kenjeran - Tambak Sumur & Tidak Berizin \\
5 & Baliho Pondok Candra Indah & Kenjeran - Tambak Sumur & Tidak Berizin \\
\hline
\end{tabular}

Dari Table 2 dapat dilihat terdapat 5 pemanfaatan Iklan dan Media Informasi yang berdiri di Ruang Milik Jalan nasional sepanjang Jl. Ir. Soekarno dan seluruh pemanfaatan tidak berizin, adapun titik pemasangan Iklan dan Media Informasi tersebut dapat dilihat pada Gambar 3 berikut :

Tidak adanya izin dari BBPJN VIII terkait pemasangan Baliho bukan berarti baliho tersebut liar, kebanyakan mereka mengurus izin di Dinas Kota/Kab meskipun ruas jalan tersebut masuk pada ruas jalan Nasional. Iklan dan media informasi merupakan salah satu sumber PAD sehingga Pemerintah Kota Surabaya merasa mempunyai hak untuk menerbitkan izin sehingga mereka mendapatkan PAD dari baliho yang berdiri. Hal tersebut terjadi akibat kurangnya koordinasi antara Pemerintah Pusat yaitu BBPJN VIII selaku penyenggara jalan nasional dengan pemerintah daerah yaitu pemerintah kota/kab disini yaitu Kota Surabaya. BBPJN sendiri sebenarnya telah melakukan sosialisasi mengenai pemanfaatan bagian-bagian jalan dengan mengundang pejabat pemerintah kab/kota, namun seringkali yang datang hanya staff biasa sehingga mereka tidak mempunyai kewenangan untuk memutuskan atau memberi masukan kepada BBPJN VIII terkait solusi yang dilakukan agar tidak ada pihak yang merasa dirugikan.Dalam hal Iklan dan Media Informasi, sedikit ada perbedaan dengan pemanfaatan lainnya karena untuk Reklame merupakan salah satu sumber pendapatan asli daerah Kota Surabaya, oleh karena itu terjadi ketimpangan dalam pengurusan izin mengenai reklame, hal tersebut membuat pihak pemanfaat mengurus izin pendirian kepada Pemerintah Daerah Surabaya. Gambar 5 berikut merupakan gambar yang diambil terkait iklan dan media informasi yang berdiri di rumija Jl. Ir. Soekarno.

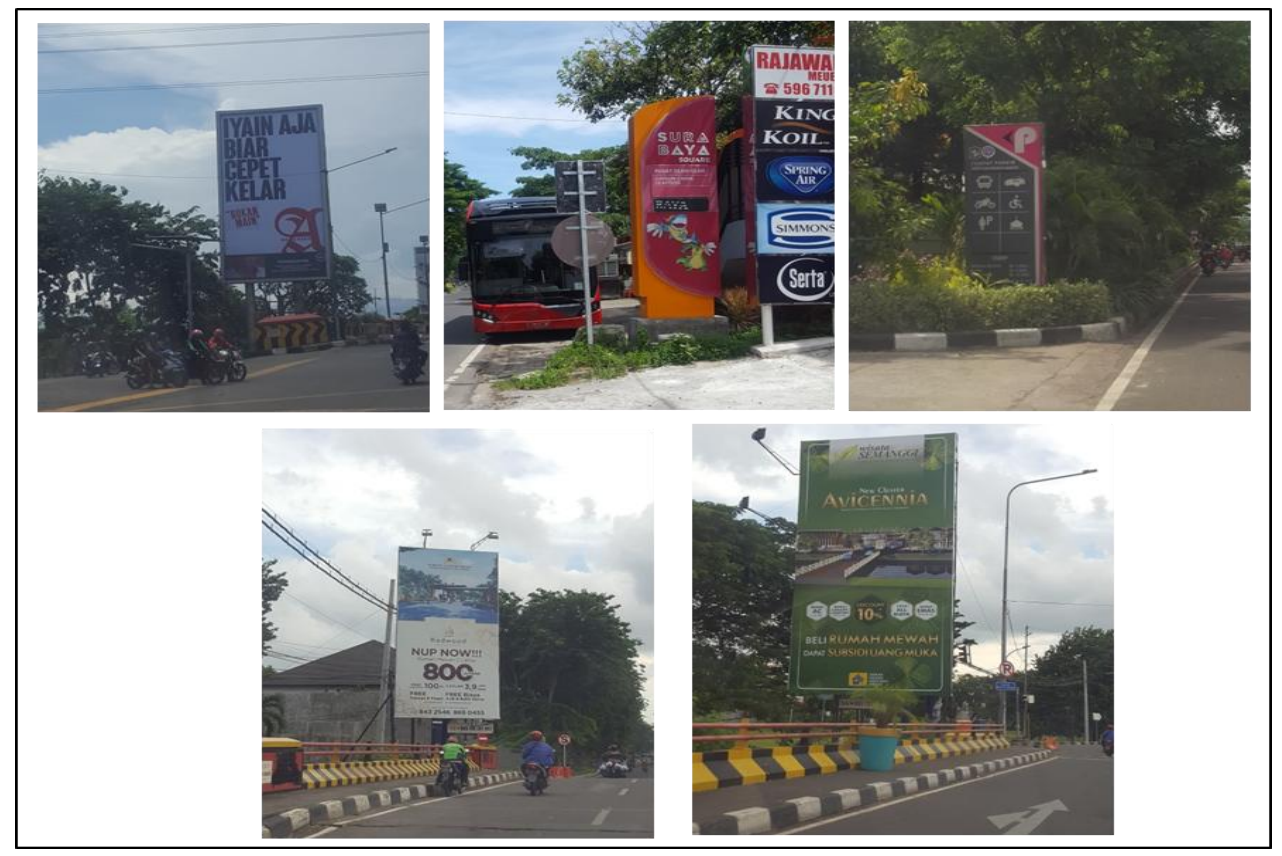

Gambar 5. Baliho di Ruas Jalan Ir. Soekarno 


\section{Akses Jalan Keluar Masuk}

Observasi ruas Jl. Ir Soekarno di mulai dari Turun Toll Tambak Sumur kearah Jl. Kenjeran, kemudian kembali kearah Tambak Sumur, dilakukan dengan melihat akses jalan keluar masuk pada mini market, supermarket, ruko, mall yang berada paja sepanjang jalan Ir. Soekarno, baiksisi kanan maupun kiri jalan, hasil observasi di tampilkan dalam Gambar 5 berikut:

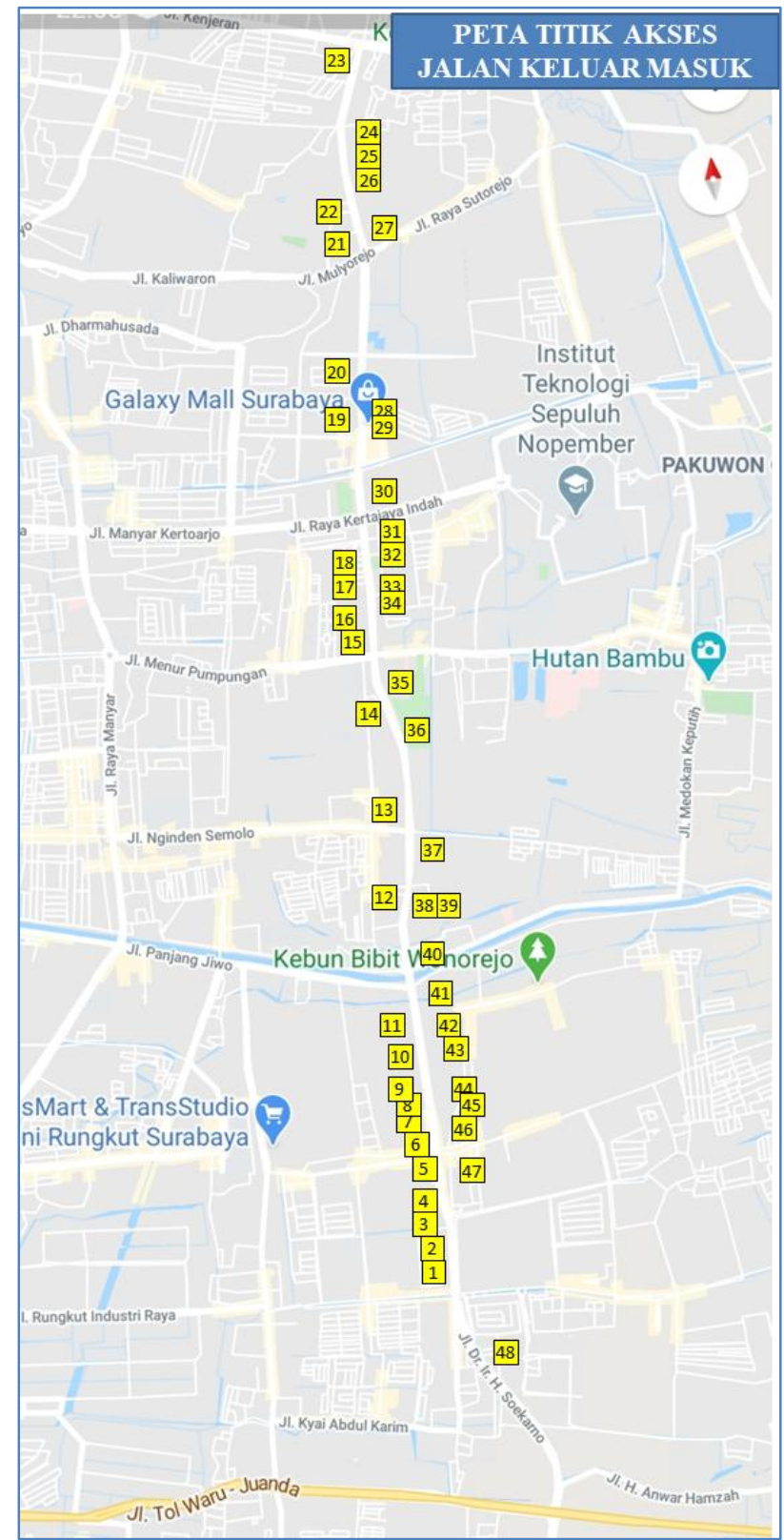

Gambar 6. Lokasi Akses Jalan Keluar Masuk di Ruas Jl. Ir. Soekarno

Gambar 6 menunjukkan adanya 48 titik lokasi akses jalan keluar masuk yang berada di sepanjang Jl. Ir. Soekarno. Terhadap data tersebut kemudian dilakukan konfirmasi atas pemanfaatan berupa akses jalan keluar masuk kepada penyelenggara jalan nasional yaitu BBPJN VIII, hasil konfirmasi tersebut dapat dilihat pada Tabel 3 berikut ini : 
Table 3. Akses Jalan Keluar Masuk di Ruas Jl. Ir. Soekarno

\begin{tabular}{|c|c|c|c|}
\hline No & Nama Perusahaan & Lokasi & Keterangan \\
\hline 1 & Alfamidi & Tambak Sumur - Kenjeran & Tidak Berizin \\
\hline 2 & Arena Ban Pro Shop & Tambak Sumur - Kenjeran & Tidak Berizin \\
\hline 3 & Indomaret Ir. Soekarno 3 & Tambak Sumur - Kenjeran & Tidak Berizin \\
\hline 4 & Ruko MERR Square City & Tambak Sumur - Kenjeran & Tidak Berizin \\
\hline 5 & Ruko Wisma Kedung Asem Indah & Tambak Sumur - Kenjeran & Tidak Berizin \\
\hline 6 & Bank Mandiri KCP Surabaya MERR & Tambak Sumur - Kenjeran & Tidak Berizin \\
\hline 7 & Ruko Indah Bordir & Tambak Sumur - Kenjeran & Tidak Berizin \\
\hline 8 & Bank Jatim Kantor Kas MERR & Tambak Sumur - Kenjeran & Tidak Berizin \\
\hline 9 & Bank Mandiri Surabaya MERR & Tambak Sumur - Kenjeran & Tidak Berizin \\
\hline 10 & Bank BRI Kanca Surabaya MERR & Tambak Sumur - Kenjeran & Tidak Berizin \\
\hline 11 & Ruko Jamkrindo dkk & Tambak Sumur - Kenjeran & Tidak Berizin \\
\hline 12 & Ruko Central Busines Park & Tambak Sumur - Kenjeran & Tidak Berizin \\
\hline 13 & SPBU 54.601 .47 & Tambak Sumur - Kenjeran & Tidak Berizin \\
\hline 14 & Ruko Kantor ADIRA dll & Tambak Sumur - Kenjeran & Tidak Berizin \\
\hline 15 & Tempat Parkir Arif Rahman Hakim & Tambak Sumur - Kenjeran & Tidak Berizin \\
\hline 16 & SMPN 19 & Tambak Sumur - Kenjeran & Tidak Berizin \\
\hline 17 & Gedung ESA SAMPOERNA & Tambak Sumur - Kenjeran & Tidak Berizin \\
\hline 18 & Ruko Mega Galaxy & Tambak Sumur - Kenjeran & Tidak Berizin \\
\hline 19 & Galaxy Mall 3 & Tambak Sumur - Kenjeran & Berizin \\
\hline 20 & Hotel Alimar & Tambak Sumur - Kenjeran & Berizin \\
\hline 21 & Ruko Este Square & Tambak Sumur - Kenjeran & Tidak Berizin \\
\hline 22 & Ruko Semen Gresik dll & Tambak Sumur - Kenjeran & Tidak Berizin \\
\hline 23 & RSIA MERR & Tambak Sumur - Kenjeran & Tidak Berizin \\
\hline 24 & SPBU & Tambak Sumur - Kenjeran & Berizin \\
\hline 25 & Hotel Dafam & Tambak Sumur - Kenjeran & Tidak Berizin \\
\hline 26 & Hotel Setia & Tambak Sumur - Kenjeran & Tidak Berizin \\
\hline 27 & Ruko Citi9 & Tambak Sumur - Kenjeran & Tidak Berizin \\
\hline 28 & Galaxy Mall 2 & Tambak Sumur - Kenjeran & Berizin \\
\hline 29 & Galaxy Mall 1 & Tambak Sumur - Kenjeran & Berizin \\
\hline 30 & Gedung MNC & Tambak Sumur - Kenjeran & Berizin \\
\hline 31 & Auto 2000 & Tambak Sumur - Kenjeran & Berizin \\
\hline 32 & Hartono Elektronik & Tambak Sumur - Kenjeran & Berizin \\
\hline 33 & Bank BCA & Tambak Sumur - Kenjeran & Tidak Berizin \\
\hline 34 & Telkom Landmark & Kenjeran - Tambak Sumur & Tidak Berizin \\
\hline 35 & Univ Kristen & Kenjeran - Tambak Sumur & Tidak Berizin \\
\hline 36 & Ruko Icon 21 & Kenjeran - Tambak Sumur & Tidak Berizin \\
\hline 37 & Ruko Grand Citi9 & Kenjeran - Tambak Sumur & Tidak Berizin \\
\hline 38 & Indomaret & Kenjeran - Tambak Sumur & Tidak Berizin \\
\hline 39 & Alfamart & Kenjeran - Tambak Sumur & Tidak Berizin \\
\hline 40 & Apartemen Bale Hingil & Kenjeran - Tambak Sumur & Berizin \\
\hline 41 & Eiger MERR & Kenjeran - Tambak Sumur & Tidak Berizin \\
\hline 42 & Superindo & Kenjeran - Tambak Sumur & Berizin \\
\hline 43 & Ruko Promenade & Kenjeran - Tambak Sumur & Berizin \\
\hline 44 & Pizza Hut & Kenjeran - Tambak Sumur & Tidak Berizin \\
\hline 45 & Burger King & Kenjeran - Tambak Sumur & Tidak Berizin \\
\hline 46 & Indomaret & Kenjeran - Tambak Sumur & Tidak Berizin \\
\hline 47 & Ruko Bernardi dll & Kenjeran - Tambak Sumur & Tidak Berizin \\
\hline 48 & Ruko XX & Kenjeran - Tambak Sumur & Berizin \\
\hline
\end{tabular}

Tabel 3 menunjukkan terdapat 48 (empat puluh delapan) pemanfaatan berupa akses jalan keluar masuk, yang sudah berizin adalah 12 akses jalan keluar masuk dan yang belum berizin 36. Pemanfaatan tersebut dilakukan oleh Perusahaan. Berikut adalah contoh dari beberapa Akses Jalan Keluar Masuk yang berizin dan belum berizin dapat dilihat pada Gambar 6 dan Gambar 7 seperti berikut : 


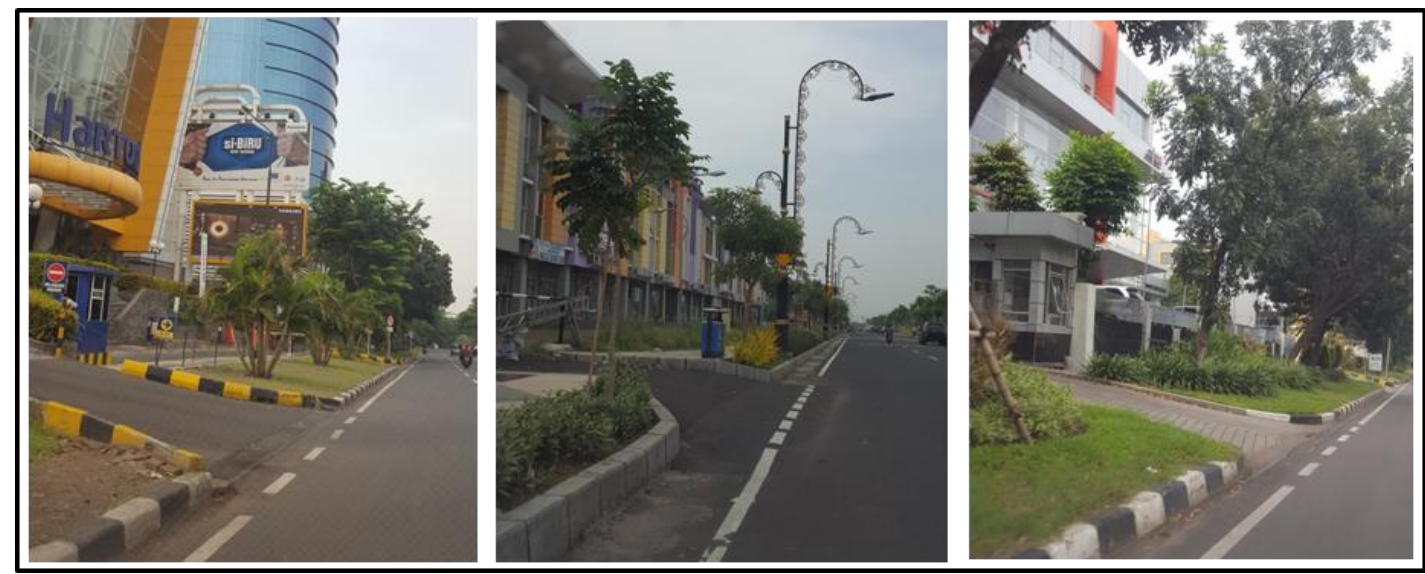

Gambar 7. Pemanfaatan Bagian-Bagian Jalan di Ruas Jalan Ir. Soekarno Yang Berizin

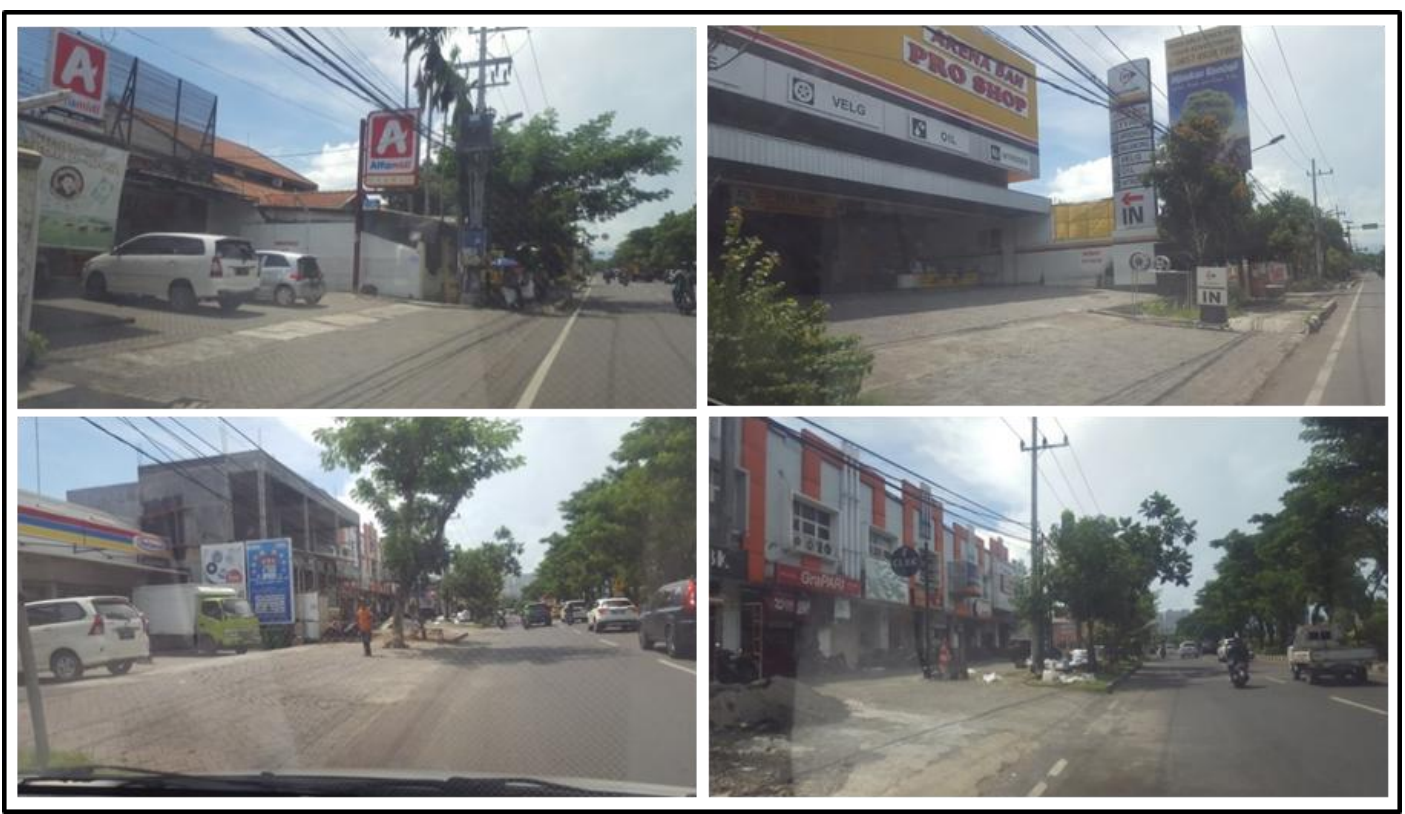

Gambar 8. Pemanfaatan Bagian-Bagian Jalan di Ruas Jalan Ir. Soekarno Yang Tidak Berizin

Gambar 8 diatas merupakan pemanfaatan jalan untuk jalan keluar masuk berupa toko, hotel, ruko yang berizin. Gambar 7 menunjukkan akses jalan keluar masuk yang belum berizin. Mengenai hal tidak adanya izin akses jalan keluar masuk dari BBPJN VIII, pemanfaat dari awal tidak mempunyai izin, atau awalnya sudah mempunyai izin namun masa izin habis dan tidak memperbaharui. Hal tersebut terjadi karena pihak pemanfaat kurang mengetahui mengenai izin pemanfaatan bagian-bagian jalan. Ciri dari Akses Jalan Keluar Masuk tidak mempunyai izin adalah, marka jalan lurus tidak putus-putus. 


\section{Pembahasan}

Berdasarkan hasil dari penelitian yang dilakukan di Jalan MERR Surabaya menunjukkan bahwa masih ada beberapa perusahaan yang memanfaatkan jalan namun belum berizin. Pemanfaatan jalan tersebut sebagian besar untuk jalan keluar masuk. Kemudian beberapa yang belum berizin adalah pemanfaatan jalan untuk iklan.

Ada beberapa hal yang menyebabkan perusahaan belum mendapatkan izin karena perizinan dilakukan tidak pada BBPJN VIII namun melakukan perizinan pada pemerintah kota. Tidak dilakukannya izin pada BBPJN VIII bisa disebabkan karena kurangnya informasi atau pengetahuan bahwa pada jalan nasional izin dilakukan pada BBPJN VIII. Pihak perusahaan atau instansi terkait merasa cukup dengan mengajukan izin pada pemerintah kota, selain hal tersebut juga dikarenakan Balai Besar Pelaksanaan Jalan Nasional VIII masih mengandalkan obyek perizinan yang datang sendiri untuk melakukan pengajuan izin dan tidak pernah menindak terhadap obyek perizinan yang tidak mempunyai izin dari Balai Besar. Pelanggaran tersebut dikarenakan belum ada personil yang khusus dalam melaksanakan monitoring dan inventarisasi terhadap pendirian obyek perizinan yang didirikan di ruas jalan nasional. Padahal hal tersebut sudah jelas tertuang di dalam Peraturan Menteri Pekerjaan Umum Nomor: 20/PRT/M/2010 tentang Pedoman Pemanfaatan Bagian-Bagian Jalan bahwa pemanfaatan ruang manfaat jalan dan ruang milik jalan selain peruntukannya meliputi bangunan dan jaringan utilitas, iklan, media informasi, bangunan-bangunan, dan bangunan gedung di dalam ruang milik jalan, wajib memperoleh izin dari penyelenggara jalan sesuai kewenangannya

Terkait dengan kondisi ini maka dapat dilihat bahwa perlunya upaya instansi untuk melakukan manajemen aset. BBPJN VIII perlu mengelola infrastruktur agar tetap bisa menjalankan fungsinya dengan baik secara terus menerus sepanjang masih dibutuhkan, secara ekonomis, efisien dan efektif. Dengan mengelola manajemen aset maka akan dapat melakukan pengambilan keputusan yang tepat. Sehingga asset yang dikelola berfungsi secara efektif dan efisien (Sugiama, 2013). Melihat masih kurangnya informasi dan pengetahuan perusahaan atau instansi akan izin ke pihak BBPJN maka sanksi harus tegas di kenakan kepada masyarakat yang melakukan pelanggaran. Sosialisasi juga harus dimaksimalkan, agar peraturan pemanfaatan dan penggunaan bagian bagian jalan yang baik dan benar di mengerti oleh pengguna jalan dan masyarakat (Hardi \& Ernawati, 2016). Selain sanksi dan sosialisasi juga perlu melakukan koordinasi dengan pemerintah kota akan tugas dan kewenangan masing - masing.

\section{KESIMPULAN}

Hasil penelitian menunjukkan terdapat 1 jaringan distribusi gas yang belum berizin, 5 iklan yang belum berizin serta 36 pemanfaatan jalan keluar masuk yang belum berizin. Pihak instansi BBPJN VIII perlu melakukan manajemen aset dengan memberikan informasi dan pengetahuan pada perusahaan atau instansi yang memanfaatkan ruang milik jalan dengan cara sosialisasi dan pemberian surat teguran atau sanksi pembongkaran pada pihak terkait sekaligus melakukan koordinasi dengan pemerintah kota akan tugas dan kewenangan masing - masing.

\section{DAFTAR PUSTAKA}

Hadi, P.L., Wasanta, T. \& Santosa, W. (2018). "Penyelenggaraan Perizinan Pemanfaatan Bagian-Bagian Jalan Nasional”. Jurnal Transportasi Vol. 18, No. 2, Agustus 2018, Hal 97-106.

Hardi, Della \& Ernawati. (2016). "Pengawasan Pemanfaatan dan Penggunaan Bagian-Bagian Jalan oleh Dinas Bina Marga Kota Pekanbaru". JOM FISIP Vol. 3, No. 1 - Februari 2016.

SEDitjenBinaMarga 14/11. Surat Edaran Nomor 14/SE/M/2011 tentang Prosedur Perizinan Pemanfaatan Bagian-Bagian Jalan Nasional. 
Soemitro, R. A. A. \& Suprayitno, H. (2018). "Pemikiran Awal tentang Konsep Dasar Manajemen Aset Fasilitas“. JurnalManajemen Aset Infrastruktur \& Fasilitas. Vol 2, Sup. 1, Juni 2018, Hal 01 - 14.

Suprayitno, H. \& Soemitro, R. A. A. (2018). "Preliminary Reflexion on Basic Principle of Infrastructure Asset Management". Jurnal Manajemen Aset Infrastruktur \& Fasilitas. Vol 2, No. 1, Maret 2018, Hal 01 - 10.

Sugiama, A Gima. (2013). Manajemen Aset Pariwisata: Pelayanan Berkualitas Agar Wisatawan Puas dan Loyal, Guardaya Intimarta, Bandung.

PerMenPU 20/10. Peraturan Menteri Pekerjaan Umum Nomor 20/PRT/M/2010 tentang Pedoman Pemanfaatan dan Penggunaan Bagian-bagian Jalan.

PP 34/06. Peraturan Pemerintah No. 34 Tahun 2006 tentang Jalan.

UU 38/04. Undang-Undang Nomor 38 Tahun 2004 tentang Jalan. 


\section{(e)ISSN 2615-1847 (p)ISSN 2615-1839}

Jurnal Manajemen Aset Infrastruktur \& Fasilitas - Vol. 4, No. 3, Juli 2020 